\title{
TEORÍAS PARA EXPLICAR EL ORIGEN, CONSTRUCCIÓN Y ESTABLECIMIENTO DE LA AGENDA SOCIOPOLÍTICA
}

\author{
Javier Carreón Guillén1: Universidad Nacional Autónoma de México \\ javierg@unam.mx
}

Jorge Hernández Valdés: Universidad Nacional Autónoma de México jorheval@unam.mx

\section{RESUMEN}

El origen, construcción y establecimiento de una agenda sociopolítica implica actores que no necesariamente se relacionan directamente, sino que utilizan medios para difundir información acerca de los temas de sus agendas. En el caso del Estado, los medios de comunicación tales como televisión, radio y prensa son empleados para influir en la opinión ciudadana cuando de la evaluación de políticas públicas se trata. Por su parte, la ciudadanía a través de las redes sociales como Twitter y Facebook ha influido en el ejercicio profesional de los comunicadores. De este modo, la influencia de los medios sobre las políticas públicas a través de la opinión pública ha sido rebasada. En este sentido, el objetivo del presente trabajo es exponer los marcos teóricos para explicar las relaciones entre los actores involucrados en el establecimiento de la agenda pública. Este ejercicio permitirá discernir los modos de influencia entre los actores y la emergencia o permanencia de temas en la agenda nacional.

\section{PALABRAS CLAVE}

Agenda - políticas públicas - medios de comunicación - sociedad civil - redes sociales.

\section{ABSTRACT}

The origin, construction and establishment of a socio-political agenda involves actors who do not necessarily relate directly, but use media to disseminate information about the topics of their agendas. In the case of the state, the media such as television, radio and newspapers are used to influence public opinion when evaluating public policy issue. Meanwhile, citizenship through social networks like Twitter and Facebook has influenced the practice of journalists. Thus, the influence of the media

1Javier Carreón Guillén: Universidad Nacional Autónoma de México javierg@unam.mx 
on public policy through public opinion has been exceeded. In this sense, the objective of this paper is to present the theoretical framework to explain the relationships between the actors involved in setting the public agenda. This exercise will discern modes of influence between the actors and the emergence and permanence of issues on the national agenda.

\section{KEYWORDS}

Schedule - public policy - media - civil society - social networking.

\section{INTRODUCCIÓN}

Una agenda es el resultado de la relación entre Estado y ciudadanía en un contexto en el que los medios de comunicación y las tecnologías de información transforman la realidad en imágenes más que en argumentos.

La construcción de una agenda supone la participación de actores que se organizan en redes y utilizan dispositivos tecnológicos para comentar, discutir, analizar, criticar y proponer contenidos alternos a los emitidos por grupos o elites en el poder.

El establecimiento de la agenda es el resultado final de la proliferación de temas circundantes en la opinión pública que previamente fueron difundidos en los medios de comunicación y comentados en las tecnologías de información.

Una agenda sociopolítica es un conglomerado de discursos, temas y tecnologías encaminados a transformar la opinión pública en simpatizantes, adherentes, militantes o disidentes políticos que ocupen los espacios disponibles para manifestar su apoyo a un sistema político, régimen de gobierno, forma de estado, clase política, opción partidista o política pública como la solución a problemáticas sociales que a menudo requieren ser resultas por la distribución de los recursos comunes.

\section{OBJETIVOS}

En este sentido, el objetivo del presente trabajo es exponer los marcos teóricos para explicar las relaciones entre los actores involucrados en el establecimiento de la agenda pública. Este ejercicio permitirá discernir los modos de influencia entre los actores y la emergencia o permanencia de temas en la agenda nacional.

\section{METODOLOGÍA}

La construcción de una agenda sociopolítica implica un procesamiento de símbolos que parten de una memoria colectica, transitan por representaciones sociales, actitudes hacia sistemas políticos y campos de poder.

El establecimiento de la agenda sociopolítica supone la emergencia de actores que se muestran como disidentes al régimen y cuestionan los temas puestos a debate por los grupos de poder. Sin embargo, este proceso llega a ser absoluto cuando las críticas y manifestaciones de inconformidad están ausentes. En ese sentido, las tecnologías de información más que los medios de comunicación inhiben la innovación y promueven la conformidad y la obediencia. 
El establecimiento de la agenda incluye dimensiones para su análisis las cuales serían:

- Crisis económicas; desaceleración y recesión de la producción y el consumo, así como escasez de recursos naturales y emergencia de grupos delictivos.

- Regímenes de gobierno y formas de Estado que determinarán las relaciones con adherentes, simpatizantes, disidentes u opositores.

- Ausencia o presencia de grupos y partidos disidentes para la competencia por el poder político.

- Ideología política, partidista o sectorial y su diseminación en los foros de debate.

- Marco jurídico para la difusión de información en los medios de comunicación.

- Acceso a las tecnologías de información y comunicación, principalmente de Internet y sus foros virtuales.

- Organización de las esferas civiles en observatorios ciudadanos y grupos vulnerables, marginados o excluidos de los medios de comunicación, tecnologías informativas, redes sociales o foros de discusión.

- Formación de opinión pública a partir de los factores esgrimidos y su influencia en las decisiones gubernamentales a través de los medios y tecnologías.

- Síntesis de la opinión ciudadana en símbolos y significados ajustados a las decisiones gubernamentales. Emisión de información relativa a temas de la agenda ciudadana. mediática, política y nacional.

- Emergencia del espíritu emprendedor por parte de actores y redes de sociales. O bien, permanencia de la conformidad y la obediencia que impide su sustitución por la innovación y propuestas alternas a las políticas públicas.

\section{DISCUSIÓN}

\subsection{Teoría de las Representaciones Sociales}

Una representación social por sí sola sería un conjunto de variables afectivas, emocionales, cognitivas y conductuales orientadas a una construcción grupal del conocimiento. Sin embargo, las representaciones sociales son más bien un contexto histórico en el que convergen una diversidad de símbolos, significados y sentidos orientados a la formación, desarrollo o extinción de un grupo en relación a la gestión de la información (Jodelet, 2011). Se trata de saberes y conocimientos cotidianos que derivan en discursos, creencias y estereotipos inherentes a algún grupo, o bien, son categorizaciones prototípicas influidas por identidades mayoritarias y minoritarias. De un modo $u$ otro, son estructuras interpretativas de la realidad y para ello, se presentan en estilos comunicativos y semióticos de interpretación de la realidad. Una vez transformadas en discursos, las representaciones sociales devienen en un pensamiento social delimitado por un objeto, grupo, sociedad o cultura, aunque también pueden ser conocimientos sociales acerca de la ambigüedad y difusión informativa. Es posible observar que esta vertiente holista de las representaciones 
sociales considera niveles discursivos en los que la gestión del conocimiento se lleva a cabo con menos recursos simbólicos y mayor afectividad.

Por su parte la vertiente estructural de las representaciones sociales considera que la diversidad de la vida cotidiana es procesada racionalmente para dar un sentido de orden a la misma y delimitar las acciones personales frente a las construcciones colectivas. Incluso, las representaciones sociales son opuestas, según tal enfoque, al conocimiento científico, aunque de el puedan haber derivado. Se trata de información procesada en símbolos que permitan ajustar comportamientos individuales en estilos de comunicación colectiva. Tal proceso involucra a los grupos en tanto existan elementos de comunicación.

No obstante, la construcción de símbolos para la comunicación y la acción práctica derivan de los medios de comunicación, además de ser observables mediante el lenguaje, los grupos construyen discursos que los diferencian de otras audiencias. En este sentido, los valores son indicadores de la representación social de un objeto mediático y su devenir en símbolos (Marina, 2010). Ello supone la incidencia de normas grupales sobre valores, creencias y opiniones que se difunden en los medios de comunicación. Es decir, la influencia de los medios implica la interpretación de sus contenidos por parte de audiencias en referencia a otros contextos como el entorno, la familia o la escuela.

Una tercera vertiente asegura que las representaciones sociales son sistemas organizadores de la realidad sin importar la fuente de información o su procesamiento, estructuran y ordenan la realidad. Tal proceso indica una relación dual entre individuos e información ya que no sólo se reproducen contenidos una procesados los símbolos, sino además se produce información haciendo más compleja la relación. En otras palabras, las representaciones sociales dotan de sentido a la realidad personal, interindividual y grupal (Velázquez, Gutiérrez \& Quijano, 2013). Ello sugiere que las representaciones sociales se sintetizan en constructos o invenciones de la realidad frente a la cual las personas asumen una postura innovadora ya que no sólo permiten su influencia, sino que al interpretar la información la diversifican aún más (Barrios, 2013). Si además agregamos el proceso comunicativo y discursivo, entonces tenemos que las representaciones sociales son símbolos prácticos para intervenir en la vida cotidiana (Barriga, Correa \& Figueroa, 2013).

En síntesis, la vertiente holista, estructuralista y sistémica de las representaciones sociales coinciden en que éstas son externas al individuo, aunque la información se procese internamente. Además, señalan que ello permite un vínculo entre los grupos y las personas de un modo tal que la realidad es procesada deductiva o inductivamente, pero definitivamente es un medio de interrelación humana.

$\mathrm{S}$ así como las redes de gestión del conocimiento son entendidas, desde la Teoría de las Representaciones Sociales, como símbolos que enlazan los saberes individuos y los procesan según necesidades y expectativas grupales frente a discursos académicos o tecnológicos que los imbrican en un intercambio de información.

Además, las redes de conocimiento serían algo más que la simple traducción de contenidos específicos en aplicaciones cotidianas, supone la intromisión de símbolos en el individuo a fin de que sus decisiones y acciones se orienten según los intereses 
de quienes emiten información y establecen temas de discusión a través de los medios de comunicación.

En el caso de las universidades públicas será posible apreciar que las representaciones sociales del conocimiento científico son diseminadas por redes que fungen como filtros de información y comunicación de los especialistas hacia los estudiantes. En este proceso los símbolos ya no sólo son compartidos, sino que son representados diferencialmente a partir de los capitales que cada individuo en lo particular y grupos en lo general poseen.

Las redes de conocimiento, en tanto filtros de información diseminan no sólo los contenidos, sino emplean mecanismos de gestión que lleva a diversificar la enseñanza y el aprendizaje de los contenidos. En el caso de las universidades públicas, el conocimiento está disponible a la comunidad con la finalidad de que se reproduzca, cuestione o innove.

Se trata de un proceso público en el que los símbolos son asimilados como significados y por ende patrimonio de quienes lo poseen, transfieren o traducen. Es aquí donde las representaciones sociales emergen como fases de objetivación y anclaje.

La objetivación implica la representación simbólica de un proceso educativo, científico o tecnológico. Al ser las TIC mayormente consumidas por la comunidad académica, la información actualizada cobra relevancia pública ya que, por ejemplo, una deserción o un hallazgo son diseminados a través de los dispositivos de información.

Precisamente, es el segundo proceso de anclaje el que explica la conversión de un simple hecho o acontecimiento en una discusión pública a través de redes de conocimiento. El anclaje consiste en el establecimiento de un significado a símbolos que por su relevancia social han sido asimilados y debatidos en los foros académicos. Es así como símbolos asociados a significados configuran representaciones que al ser diseminadas, discutidas, conceptualizadas y difundidas se transforman en representaciones sociales. En este sentido, la gestión del conocimiento no sólo implica el acercamiento entre especialistas, sino además requiere de su distribución en los grupos de conocimiento. Además, los contenidos de cualquier orden, al estar asequibles a la comunidad universitaria son fuente de representaciones ya no sólo medios que facilitan, inhiben o determinan el conocimiento.

El advenimiento de símbolos y significados respecto a una comunidad sugiere la producción o reproducción no sólo de conocimientos, sino la emergencia de percepciones, creencias, actitudes, habilidades, decisiones y comportamientos.

En el orden expuesto, la gestión de conocimiento en una universidad pública atraviesa etapas que van de la producción hasta la reproducción de información especializada y expuesta al escrutinio de la comunidad universitaria.

La gestión del conocimiento inicia con la objetivación de la información para que, una vez naturalizada, sea anclada a la vida cotidiana de la comunidad. Este proceso emerge de valores, normas y tradiciones académicas que permiten la emergencia de temas y contenidos los cuales en algún momento serán convertidos en información especializada y por ende central en las representaciones sociales tanto de la gestión como del propio conocimiento. 
En efecto, las representaciones sociales incluyen dos dimensiones, una central y otra periférica desde las cuales la información es almacenada en el núcleo central una vez que ha sido fragmentada, analizada, discutida y conceptualizada en la zona periférica. Es decir, la estructura de gestión del conocimiento, desde la Teoría de las Representaciones Sociales, alude a dos niveles de acceso a la información, producción y reproducción.

La interrelación entre el núcleo central y la zona periférica incide en la gestión del conocimiento ya que las decisiones orientadas a la producción, distribución, reproducción, crítica e innovación son categorías que permiten diferenciar a las representaciones sociales de otros procesos inherentes a la gestión del conocimiento. Empero, la producción del conocimiento, a diferencia de la reproducción de contenidos académicos, posee una dinámica diferente ya que mientras se produce información especializada, la lectura y traducción de esos contenidos puede ser más inmediata. En tanto que la producción del conocimiento requiere de una naturalización académica que consiste en la presentación de hallazgos ante la comunidad científica o tecnológica. Son estas dos últimas las que definirán la entrada de los nuevos contenidos en la agenda universitaria.

En síntesis, la gestión del conocimiento va desde su producción hasta su reproducción y tiende a emitir símbolos que al ser compartidos por una comunidad inhiben o facilitan la emergencia de significados. Las evidencias de este proceso de representaciones sociales las encontramos en la centralización de conocimientos y en la periferia de los temas que se debaten al interior de la comunidad universitaria. En el núcleo central, los contenidos son considerados clásicos de la educación, ciencia y tecnología mientras que en la periferia los temas son asumidos como hipótesis de trabajo que podrán aspirar a ser incorporados en el núcleo central del conocimiento. Para ello, las hipótesis deberán transitar por una objetivación, naturalización y anclaje porque serán tratados como símbolos discursivos y significados interpretativos de los grupos que los producen, discuten o reproducen.

Si de grupos discursivos de poder se trata, entonces la Teoría de los Campos Discursivos ofrece los ejes de análisis que conduzcan a una explicación del por qué los hallazgos científicos o los problemas educativos son transformados en símbolos centrales o periféricos según su grado de relevancia para la comunidad académica.

\subsection{Teoría del Establecimiento de la Agenda}

La producción, gestión y reproducción del conocimiento están vinculadas con el establecimiento de una agenda académica. En cierto modo la información es transformada en temas centrales de discusión gracias a los medios de comunicación. La brecha existente entre científicos y lectores es reducida por la injerencia de los medios de comunicación. En principio, los hallazgos científicos son sesgados o reducidos ya que la difusión de la ciencia amplia su espectro de lectores a medida que simplifica sus contenidos de producción del conocimiento (Maric, 2012). Es decir, los medios de comunicación asumen que los lectores son neófitos en los temas científicos y por ende simplifican los contenidos a menudo aplicándolos a una actividad cotidiana. Este fenómeno es conocido como establecimiento de agenda ya 
que los temas son seleccionados por los medios de comunicación y transferidos a sus audiencias en forma de reportajes, noticias, columnas o programas.

El establecimiento de la agenda no es exclusivo de las esferas civiles ya que las comunidades académicas también son susceptibles de ser influidas por coloquios, simposiums, congresos, encuentros, talleres, conferencias o seminarios que actualmente se transmiten por los canales oficiales de las universidades o a través de los canales estudiantiles (Fernández, 2012). Además las gacetas, semanarios o periódicos de las universidades también promocionan, sintetizan o critican los eventos en los que se presentan los avances científicos. Los medios de comunicación al interior de las universidades también construyen opinión pública a partir de sesgar los contenidos y emitir sólo una parte de ellos a la comunidad estudiantil o académica.

El establecimiento de la agenda requiere de representaciones, campos, habitus, capitales, actitudes, competencias, actores y redes en torno a la producción, gestión y reproducción del conocimiento.

Los medios de comunicación de las universidades asumen que la comunidad académica y estudiantil sólo se interesará por determinados temas que precisamente se pueden observar en el núcleo central de las representaciones sociales del conocimiento científico. O bien, la cobertura de los medios de comunicación universitarios también está enfocada en aquellos temas emergentes y periféricos a la agenda científica (Álvarez, 2012).

Se trata de contenidos emitidos por grupos de poder que determinan a través de discursos los ejes de discusión y los temas de debate. En este sentido, los campos de poder fungen como escenarios de contienda discursiva en la que los medios de comunicación universitarios inclinan la balanza hacia determinados tópicos (Fortich y Moreno, 2012).

En tanto habitus adquiridos, los conocimientos que se establecen a través de los medios de comunicación universitarios generan disposiciones en las comunidades académicas y estudiantiles a fin de orientar la construcción de una agenda universitaria.

Son los medios de comunicación quienes enaltecen los recursos y repertorios culturales de los grupos discursivos de poder. La formación de capitales simbólicos no podría explicarse sin la intervención de los medios de comunicación que en la universidad funcionan como voz oficial de los científicos más renombrados, citados o galardonados.

La recepción de la información difundida en los medios de comunicación es categorizada en rubros de valor para orientar las decisiones de consumo de los hallazgos científicos más mediáticos. Difícilmente, un descubrimiento científico sería aquilatado por una comunidad sin la intervención de algún medio de comunicación. En tal proceso, la formación de actitudes afectivas más que racionales está presente en las comunidades estudiantiles y académicas. Los medios de comunicación enaltecen hallazgos que luego los estudiantes y profesores se encargarán de asimilar para apoyar su inserción en la agenda universitaria.

La difusión de hallazgos científicos abre la discusión sobre su reproducción y las competencias que se requieren para su efectiva transferencia a las audiencias de los 
medios de comunicación universitarios (Borjas, 2011). A menudo, los contenidos científicos requieren de competencias eficientes, eficaces y efectivas que simplifiquen la información, le asignen una aplicación cotidiana y justifiquen su inserción en la agenda universitaria. Se requiere de competencias que reproduzcan el conocimiento a partir de la difusión que los medios de comunicación hacen de los hallazgos científicos.

Sin embargo, existen contenidos de relleno que pueden derivar en el protagonismo de grupos disidentes a la promoción de la ciencia y tecnología al interior de una universidad. Se trata de actores dispuestos a innovar para ser visibles ante las audiencias. En estos casos, los medios de comunicación también tienen una función relevante ya que minimizan sus argumentos disidentes al maximizar la lógica de los grupos de poder.

En síntesis, el establecimiento de una agenda universitaria supone la emergencia de contenidos y temas periféricos a las representaciones sociales de las comunidades científicas, académicas o estudiantiles. Subyace de campos discursivos de poder, es adquirida en forma de habitus y confinada a repertorios o acervos culturales desde las que se producen actitudes afectivas que no cuestionan la estructura de poder o el establecimiento mismo de una agenda universitaria. En cambio, la formación de competencias profesionales se contrapone al advenimiento de actores disidentes y redes de improvisación que amenazan el establecimiento de la agenda.

\subsection{Teoría del Espíritu Emprendedor}

Una consecuencia de los contextos inciertos, riesgosos e inseguros es el espíritu emprendedor. Observado en las organizaciones al momento de efectuarse un declive en las relaciones de producción o humanas, el emprendedurismo es el resultado de una serie de vicisitudes que resaltan las relaciones de confianza, compromiso, lealtad, afinidad, empatía e innovación (Botero, Álvarez \& González, 2012).

El espíritu emprendedor es entendido como una serie de valores, normas, creencias, percepciones, habilidades, decisiones y acciones orientadas al logro de objetivos y metas a medida que los recursos para alcanzarlos escasean (Cardon, Gregoire, Stevens \& Patel, 2013).

El emprendedurismo permite diferenciar a los grupos conformistas de los innovadores. En una situación de escasez y crisis de resultados, los individuos conformistas se adhieren a pautas establecidas mientras que aquellas personas disidentes producen ideas divergentes a las estructuras organizacionales y normas grupales (Cerrón, 2010).

Otra diferencia sustancial es la formación de minorías innovadoras frente a grupos mayoritarios, conformistas y ortodoxos. Los problemas organizacionales que inhiben la producción, gestión y reproducción de conocimiento a menudo son abordados por los grupos ortodoxos desde sus recursos y capacidades (Cordón, Agote \& Rubio, 2011). En cambio, las minorías innovadoras generan comportamientos diferentes porque sus decisiones se llevan a cabo desde la disidencia. Mientras que los grupos mayoritarios buscan la utilidad y la ganancia, los grupos minoritarios persiguen 
estilos de vida que los identifiquen con su situación económica, política y social (Danes \& Juyoung, 2013).

Sin embargo, el emprendimiento no sólo es un producto del establecimiento de la agenda, es ante todo un proceso inverso a los temas establecidos ya que representan objetivos contrarios a las normas sociales y grupales, las tradiciones y los usos locales (Díaz, Hernández \& Roldán, 2012).

El emprendimiento es un estilo de vida que genera conocimientos y en tanto información novedosa, contrasta con la difusión de temas establecidos por las esferas políticas. En ese sentido, resulta paradójico que las tecnologías de información surjan de ideas innovadoras que después se ajustan a las exigencias del mercado y las políticas públicas (Hallak, Brown \& Lindsay, 2012).

Es por ello que el establecimiento de la agenda tiene como principal indicador al surgimiento del emprendedurismo ya que inserta a las esferas sociales a una dinámica de escasez y competencia por los recursos (Hazlina, Mohd \& Rohaida, 2012).

Una agenda que no produce individuos emprendedores esta condenada a ser sustituida por otra ya que la innovación es fundamental para que el Estado se relacione con la sociedad (Jyoti \& Jyoti, 2011).

En el caso de la seguridad pública que para fines del presente estudio es representada socialmente como percepciones de inseguridad, los hallazgos reportados en el estado del conocimiento señalan que el Estado antepone sus intereses económicos sobre la xenofobia de grupos sociales que atribuyen delitos a migrantes. La controversia entre las autoridades locales y las organizaciones xenofóbicas develó la tendencia de la prensa respecto a la legalización de migrantes a fin de que pudiesen laborar en proyectos de inversión extranjera. La reactivación de la económica en un contexto de crisis hace que el Estado en lugar de inhibir la migración promueva su incorporación en los empleos de mayor riesgo.

Las políticas públicas al ser instrumentos del poder político, son difundidas por los canales de comunicación para en un caso ser cuestionadas y en otro ser aceptadas. Es decir, los temas de orden económico parecen sobreponerse a los intereses locales que en el caso de las comunidades académicas y estudiantiles penetran su esfera de representaciones de un modo tal que el tema de la privatización resulta más importante que la seguridad o la conservación ambiental.

Precisamente, en el estudio relativo al establecimiento de una agenda hídrica, las autoridades implementaron tarifas y tandeos para incentivar la participación política de los usuarios del servicio público. Más allá de la situación de escasez en algunas colonias, los residentes locales desarrollaron estilos de vida frugales que complementaron el tandeo e incluso el aumento de las tarifas.

Respecto a la inserción de las redes sociales virtuales y los foros de discusión a través de Internet, los trabajos reportados en el estado del conocimiento resaltan el papel de las tecnologías de información en contraste con las funciones de los medios de comunicación.

Se trata de un proceso en el que la formación de disposiciones indica habitus de consumo de información que son trasladados del núcleo central de las 
representaciones sociales a la periferia discursiva de los grupos que promueven los temas de discusión.

La conformación es espacios discursivos supone que las representaciones sociales más arraigadas en torno a la clase política se han convertido en percepciones, creencias y valores que permiten la diseminación del conocimiento en forma de imágenes más que argumentos.

En esta fase, la construcción de una agenda se torna más complicada ya que las imágenes conllevan afectos y emociones que pueden hacer desistir a las audiencias de su consumo de información, o bien, radicalizar sus posturas y demandas de información.

Sin embargo, luego de que los medios de comunicación y las tecnologías de información se han encargado de diversificar la información hasta un punto tal que el lector de periódicos centra su atención en las fotos, el consumidor de programas televisivos enfoca su interés en personajes ficticios, el radioescucha enfatiza las frases de comunicadores o el usuario de twitter y facebook comenta los estados de animo de sus contactos, entonces el establecimiento de una agenda ha entrado en su fase terminal.

La ausencia de discusión, así como la emergencia de códigos grupales disipó los temas de la agenda y los transformó en materia inerte para su deliberación. Es la etapa final del establecimiento de la agenda indicada por la ausencia de análisis, crítica y síntesis de la información.

No obstante, quedan pendientes algunos procesos que inciden en la construcción de temas. Tal es el caso de la identidad, la influencia o la indefensión como efectos colaterales de la categorización de imágenes, palabras frases y discursos alrededor de temas establecidos.

La identidad ha sido estudiada como un fenómeno y proceso de los grupos que comparten sentidos de pertenencia, estilos de vida y uso de recursos. La formación de capitales simbólicos es afectada por decisiones que privilegian a un grupo respecto a otro. La deliberación de temas es determinada por la elección de acciones que competen a un grupo. Incluso el uso de dispositivos tiene como fundamento la pertenencia a un grupo.

En el caso de la influencia social los grupos mayoritarios han sido también blanco de persuasión de grupos minoritarios. Las decisiones de la mayoría también cobran relevancia frente a los estilos de comportamientos de las minorías. De hecho, el establecimiento de una agenda es un fenómeno de influencia de una minoría sobre la mayoría. Así que el poder de las decisiones minoritarias atraviesa las estructuras sociales, sus contornos informativos y representaciones sociales.

Por último, la indefensión es el resultado principal de las situaciones críticas por las que los grupos se someten. La desesperanza es un producto del establecimiento de la agenda para los grupos disidentes o alternos a los temas que predominan en los medios de comunicación. a medida que la información oficial se intensifica propicia sentimientos de indefensión en aquellos grupos opositores al régimen.

En el futuro, el establecimiento de una agenda versará ya no sobre los temas, ni los actores o las tecnologías, sino más bien consistirá en la relación de las imágenes y las experiencias cotidianas. A mayor proximidad entre los símbolos y los recuerdos, 
habrá mayor satisfacción personal y al mismo tiempo desvinculación social, aunque tal experiencia se viva a través de tecnologías compartidas.

La relación entre gobernantes y usuarios se desarrollará desde tecnologías capaces de procesar iniciativas y leyes en tiempo real dadas las preferencias electorales o de cualquier índole de los usuarios.

Los sistemas políticos serán percibidos como corolarios de decisiones colectivas que se podrán dirimir en cuestión de segundos gracias a la conversión hologramática del voto, manifestación, plebiscito o escrutinio público.

Las reformas económicas, políticas, ambientales o sociales serán establecidas como temas adyacentes al confort personal en menoscabo de la colectividad, sobretodo aquellos sectores vulnerables, marginados o excluidos de las redes informativas.

En el futuro las relaciones entre élites habrán succionado a las mayorías y minorías. La gobernanza de estas elites ya no requerirá del establecimiento de una agenda, ni de la construcción de temas colectivos, sino más bien dependerá del abastecimiento energético que las tecnologías necesitarán para llevar a cabo las decisiones tomadas desde el confort personal.

\section{CONCLUSIÓN}

Una agenda es el resultado de la relación entre Estado y ciudadanía en un contexto en el que los medios de comunicación y las tecnologías de información transforman la realidad en imágenes más que en argumentos. La construcción de una agenda supone la participación de actores que se organizan en redes y utilizan dispositivos tecnológicos para comentar, discutir, analizar, criticar y proponer contenidos alternos a los emitidos por grupos o elites en el poder.

El establecimiento de la agenda es el resultado final de la proliferación de temas circundantes en la opinión pública que previamente fueron difundidos en los medios de comunicación y comentados en las tecnologías de información.

Una agenda sociopolítica es un conglomerado de discursos, temas y tecnologías encaminados a transformar la opinión pública en simpatizantes, adherentes, militantes o disidentes políticos que ocupen los espacios disponibles para manifestar su apoyo a un sistema político, régimen de gobierno, forma de estado, clase política, opción partidista o política pública como la solución a problemáticas sociales que a menudo requieren ser resultas por la distribución de los recursos comunes.

La construcción de una agenda sociopolítica implica un procesamiento de símbolos que parten de una memoria colectica, transitan por representaciones sociales, actitudes hacia sistemas políticos y campos de poder. El establecimiento de la agenda sociopolítica supone la emergencia de actores que se muestran como disidentes al régimen y cuestionan los temas puestos a debate por los grupos de poder. Sin embargo, este proceso llega a ser absoluto cuando las críticas y manifestaciones de inconformidad están ausentes. En ese sentido, las tecnologías de información más que los medios de comunicación inhiben la innovación y promueven la conformidad y la obediencia.

\section{REFERENCIAS}


Botero, J., Álvarez, F. \& González, M. (2012). Modelos de internacionalización para las pymes. Revista Minister, 20, 63-90

Cardon, M., Gregoire, D., Stevens, C. \& Patel, P. (2013). Measuring entrepreneurial passion: conceptual foundations and scale validation. Journal of Business Venturing, 28, 373-396

Cerrón, L. (2010). El papel del mercado en la construcción de los modelos de formación profesional: la mercantilización del sistema. Reifop, 13, 54-63

Cordón, E., Agote, Á. \& Rubio, E. (2011). La cooperación trasnacional entre pymes, una respuesta al desafío de la globalización: la posición de la Unión Europea. Primer Congreso de Ciencias Regional de Andalucía, España.

Danes, S. \& Juyoung, J. (2013). Copreneural identity development during new venture creation. Journal of Family Business Management, 3, 45-61

Díaz, C., Hernández, R. \& Roldán, J. (2012). A structural model of the antecedents to entrepreneurial capacity. International Small Business Journal, 30, 850-872

Fazio, R. H. (2011). A fundamental conceptual distinction...Gone unnoticed. In R. M. Arkin (Ed.), Most underappreciated: 50 prominent social psychologists describe their most unloved work (pp. 72-76). New York: Oxford University Press.

Gil, C. (2010). Comunicadores corporativos: desafíos de una formación profesional por competencias en la era global. Cuadernos, 33, 49-59

Hallak, R., Brown, G. \& Lindsay, N. (2012). The place identity performance relationships among tourism entrepreneurs: a structural equation modeling analysis. Tourism Management, 33, 143-154

Han, H. A., Czellar, S., Olson, M. A., \& Fazio, R. H. (2010). Malleability of attitudes or malleability of the IAT? Journal of Experimental Social Psychology, 46, 286-298.

Hazlina, N., Mohd, A. \& Rohaida, S. (2012). Nurturing intrapreneurship to enhance job performance: the role of pro-intrapreneurship organizational architecture. Journal of Innovation Management in Small \& Medium Entreprises, , 9, 1-9

Jodelet, D. (2011). Returning to past features of serge Moscovici Theory to feed the future. Paper on Social Representations, 20, 1-39

Jones, C. R., \& Fazio, R. H. (2010). Person categorization and automatic racial stereotyping effects on weapon identification. Personality and Social Psychology Bulletin, 36, 1073-1085. 
Jones, C. R., Fazio, R. H., Vasey, M. W. (2012). Attentional control buffers the effect of public-speaking anxiety on performance. Social Psychological and Personality Science, 3, 556-561.

Jones, C. R., Olson, M. A., \& Fazio, R. H. (2010). Evaluative conditioning: The "How" question. In M. P. Zanna \& J. M. Olson (Eds.), Advances in Experimental Social Psychology (Vol. 43, pp. 205-255). San Diego: Academic Press.

Jones, C. R., Vilensky, M. R., Vasey, M. W., \& Fazio, R. H. (2013). Approach behavior can mitigate predominately univalent negative attitudes: Evidence regarding insects and spiders. Emotion, 13, 989-996.

Jyoti, J. \& Jyoti S. (2011). Factors affecting orientation and satisfaction of women entrepreneurs in rural India. Annals of Innovation Entrepreneurships, 2, 1-8

Londoño, C. \& Cardona, H. (2011). Estado del arte de los recursos para el desarrollo. Revista Ciencias Estratégicas, 19, 35-54

Long, H. (2013). The relationships among learning orientation, market orientation, entrepreneurial orientation, and firm performance. Management Review, 20, 3746

Pietri, E. S., Fazio, R. H., \& Shook, N. J. (2012). Valence weighting as a predictor of emotional reactivity to a stressful situation. Journal of Social and Clinical Psychology, 31, 746-777.

Pietri, E. S., Fazio, R. H., \& Shook, N. J. (2013a). Recalibrating positive and negative weighting tendencies in attitude generalization. Journal of Experimental Social Psychology, 49, 1100-1113.

Pietri, E. S., Fazio, R. H., \& Shook, N. J. (2013b). Weighting positive versus negative: The fundamental nature of valence asymmetry. Journal of Personality, 81, 196208.

Rante, Y. \& Warokka, A. (2013). The interrelative nexus of indigenous economic growth and small business development: do local culture, government role, and entrepreneurial behavior play the role? Journal of Innovation Management in Small E Medium Enterprises. 19, 1-19

Rodríguez, G. (2011). Apropiación y masificación de las tecnologías de la información y las comunicaciones en las cadenas productivas como determinantes para la mipymes. Criterio Libre, 15, 213-230

Rojas, R., García, V. \& García, E. (2011a). The influence on corporate entrepreneurship of technological variables. Industrial management $\mathcal{E}$ Data System, 111, 984-1005 
Rojas, R., García, V., Ramírez, A. (2011b). How can we increase spanish technology firm. Journal of Knowledge Management. 15, 759-778

Shook, N. J., \& Fazio, R. H. (2011). Social network integration: A comparison of same-race and interracial roommate relationships.Group Processes $\mathcal{E}$ Intergroup Relations, 14, 399-406.

Sobrados, L., Fernández, E., Couce, A., Ceinos C. \& García, R. (2011). Ámbitos y procesos de la orientación en formación profesional. Revista Skepsis, 2, 675-741

Vasey, M. W., Harbaugh, C. N., Buffington, A. G., Jones, C. R., \& Fazio, R. H. (2012). Predicting return of fear following exposure therapy with an implicit measure of attitudes. Behaviour Research and Therapy, 50, 767-774.

Vasey, M. W., Vilensky, M. R., Heath, J. H., Harbaugh, C. N., Buffington, A. G., \& Fazio, R. H. (2012). It was as big as my head, I swear! Biased spider size estimation in spider phobia. Journal of Anxiety Disorders, 26, 20-24.

Young, A. I., \& Fazio, R. H. (2013). Attitude accessibility as a determinant of object construal and evaluation. Journal of Experimental Social Psychology, 49, 404-418.

Yuangion, Y. (2011). The impact of strong ties on entrepreneurial intention. An empirical study based on the mediating role of self-efficacy. Journal Entrepreneurship, 3, 147-158

Zampetakis, L. \& Moustakis, V. (2013). Entrepreneurial behavior in the Grekk public sector. Emerald, 13, 1-7

Zavala, J. (2012). La vigilancia tecnológica como una herramienta para la gestión de la información. Cuadernos de Gestión, 12, 105-124 